PRITCHARD, Bill. Regoverning Markets: A Place for Small-Scale Producers in Modern Agrifood Chains? Journal of Agrarian Change, v. 9, n. 3, p. 449-452, 2009.

REARDON, Thomas; BERDEGUE, Julio A. The rapid rise of supermarkets in Latin America: challenges and opportunities for development. Development policy review, v. 20, n. 4, p. 371-388, 2002.

REARDON, Thomas; BERDEGUÉ, Julio A. The retail-led transformation of agrifood systems and its implications for development policies. Latin American Center for Rural Development (RIMISP), Santiago, Chile, 2006.

SILVEIRA, Maria Laura; SANTOS, Milton. O Brasil: território e sociedade no início do século XXI. Rio de Janeiro: Record, 2001.

STEEL, Carolyn. Hungry city: How food shapes our lives. Random House, 2013.

SUPERMERCADO MODERNO, Relatório Anual, ano 41, nº 4, 2010. The Food Trust. Philadelphia Healthy Corner Store Network, Philadelphia Department of Public Health, 2014.

WISKERKE, Johannes SC. On places lost and places regained: Reflections on the alternative food geography and sustainable regional development. International planning studies, v. 14, n. 4, p. 369-387, 2009.

\section{SISTEMA NACIONAL DE SEGURANÇA ALIMENTAR E NUTRICIONAL NA DINÂMICA DE ESTADO: ABRANGÊNCIA E LIMITES DA POLÍTICA SOCIAL}

Raimundo Pires Silva Helena Carvalho De Lorenzo

Resumo: Por que as políticas sociais de Segurança Alimentar e Nutricional, enquanto uma ação de Estado de garantia de direitos e dever do Estado, não consolidaram a plenitude dos seus objetivos? O presente artigo busca apontar alguns aspectos relacionados ao fato de que, mesmo exitosas, essas políticas sociais estabelecidas pelo arcabouço do Sistema Nacional de Segurança Alimentar e Nutricional (SISAN), implantadas pelo governo democrático, de cunho centro-esquerda do presidente Lula, e continuadas pelo governo sucessor da presidenta Dilma, não concluíram os objetivos da estratégia Fome Zero.

Palavras-chave: Estado; Políticas Públicas; Segurança Alimentar.

Abstract: Why the social policies of Food and Nutrition Security, as a State action guaranteeing the rights and duty of the State, did not consolidate with fullness its objectives? This article seeks to point out some aspects related to the fact that, even if successful, these social policies established by the framework of the National System of Food and Nutrition Security (SISAN), implemented by the democratic government, center-left of President Lula, and continued by the successor government of President Dilma, did not complete your objectives of the Zero Hunger strategy.

Keywords: State; Public policy; Food Nutrition. 


\section{Introdução}

Por que as políticas sociais de Segurança Alimentar e Nutricional, em quanto uma ação de Estado de garantia de direitos e dever do Estado, não consolidaram a plenitude dos seus objetivos? O presente artigo busca apontar alguns aspectos relacionados ao fato de que mesmo exitosas essas políticas sociais estabelecidas pelo arcabouço do Sistema Nacional de Segurança Alimentar e Nutricional (SISAN), implantadas pelo governo democrático, de cunho centro-esquerda do presidente Lula, e continuadas pelo governo sucessor da presidenta Dilma, não concluíram os objetivos da estratégia Fome Zero.

Do ponto de vista institucional o SISAN inovou ao atribuir ao Estado a responsabilidade da questão alimentar, tendo quanto prioridade o atendimento à população em situação de Insegurança Alimentar. Ou seja, atos de governo que determinaram um padrão de proteção social e a distribuição de bens e serviços públicos que garantissem o direito das pessoas à alimentação adequada, com a constituição de mecanismos (programas e ações) que as habilitassem ao acesso ao alimento de qualidade e de resolução do espectro da fome, bem como, da produção desse alimento. Apesar dos resultados expressivos do SISAN, permaneceu no país um significativo contingente de pessoas em situação de Insegurança Alimentar, esta constatação é que está em questão na presente análise.

Do ponto de vista do método, o artigo está apoiado em uma compreensão dialética da História que interpreta os fenômenos através de sua ação recíproca, da contradição inerente aos fenômenos e da mudança dialética que ocorre na natureza e na sociedade.

Nesta direção, Boschetti (2015) mostrou que a investigação dialética da realidade social envolve a analise da totalidade concreta, indicando que cada fenômeno pode ser compreendido como um momento do todo. Um fenômeno social (e aqui se inserem as políticas sociais de Estado) é um fato histórico na medida em que é examinado como momento de um determinado todo e desempenha uma função dupla: definir a si mesmo e definir o todo, sendo ao mesmo tempo produtor e produto, conquistando o próprio significado e ao mesmo tempo conferindo sentido mais amplo ao fato.

Assim, o fenômeno social analisado deve ser compreendido em sua múltipla causalidade, bem com sua múltipla funcionalidade. Entretanto isso não significa que a pesquisa de avaliação dos fenômenos sociais deve conhecer todos os aspectos da realidade e oferecer um quadro total dela Boschetti
(2015). Na verdade, os fatos expressam um conhecimento da realidade se forem compreendidos como fatos de um todo dialético, isto é, determinados e determinantes desse todo. Assim, não podem ser entendidos como fatos isolados.

$\mathrm{O}$ estudo assim considerou a multidimensionalidade da política pública analisada como um aspecto a ser considerado. Por esta razão apoiou-se em uma concepção de análise e avaliação de politicas publicas como alternativa da abordagem racional e sequencial, até para dar conta da dimensão contraditória destas, arraigada na natureza do Estado, buscou ainda fundamentar-se em uma concepção de análise que propõe dimensão diversa e conflitante da sociedade civil. Boschetti (2015)

Do ponto de vista das estratégias de pesquisa, o estudo fundamentou-se em literatura especifica sobre avaliação de políticas publicas, considerando principalmente a perspectiva a que considera a importância do avaliador na escolha dos sinalizadores da realidade, isto é, a presença de certa realidade selecionada pelo pesquisador e de decisões, conscientes ou não, tomadas pelo avaliador. É o conjunto dessas opções e preferências que definirá o tipo de avaliação do estudo eleito. Tais escolhas integram o que se pode chamar de estratégia de avaliação, conceito que, entretanto, abrange as decisões metodológicas (DRAIBE, 2001). Foram realizadas pesquisas em fontes secundárias, particularmente relatórios do CONSEA, dados e series históricas, fornecidas pelo IBGE e RAIS. Pode ainda ser considerado como um estudo de natureza exploratória, com preocupações qualitativa e descritiva.

O artigo está organizado em seis seções, sendo esta introdução, a primeira seção. Na segunda apontam-se elementos teóricos para a compreensão das ações de Estado na construção de políticas publicas, visando responder questão apontada no início, bem como, contribuir na discussão teóricometodológica acerca da avaliação de políticas sociais. Na terceira apresentase um histórico da formação do Sistema Nacional de Segurança Alimentar e Nutricional (SISAN), suas diretrizes e instancias de gestão, mostrando sua ligação com o Programa Fome Zero. Na quarta seção o artigo aponta ações publicas implementadas de cooperação e o envolvimento da agricultura familiar como uma das ações prioritárias da politica. Na quinta seção são apresentados dados e informações que apontam para a inflexão da estratégia que deu origem ao SISAN, o programa Fome Zero, a partir de alguns indicadores de redução do gasto publico e outros indicadores considerados significativos. Finalmente, a ultima seção expõe uma reflexão sobre a abrangência dos resultados e os limites do SISAN sobre a vida de todos os 
cidadãos, de uma forma mais abrangente. O foco da análise é a questão da ação do Estado, a partir da abordagem sobre as politicas sociais de SAN.

\section{Politicas publicas como dimensão do estado contemporâneo}

Para compreender a política pública (conceito que engloba o de políticas sociais) como a dimensão mais contemporânea da ação de Estado, nesta seção ressalta-se, de forma sucinta, a trajetória do papel do Estado no desenvolvimento do sistema capitalista, na economia e no pensamento econômico.

Tendo como referência OLIVEIRA (2012) apresenta-se a seguir a seguinte periodização do papel do Estado no cenário mundial, mais especificamente nos países desenvolvidos:

i. No período nascente da sociedade capitalista o papel do Estado é crucial para a constituição da burguesia como também para liquidar as resistências do antigo regime que se opunha ao seu florescimento ${ }^{3}$; ii. No período do capitalismo competitivo, ao Estado caberia apenas a tarefa de garantir as condições externas para reprodução do sistema e atuar par corrigir falhas localizadas na alocação de recursos que levam à perda de competitividade

iii. Quando o sistema competitivo desmorona e é substituído por estruturas não competitivas, o mercado perde o seu poder autorregular e a lei de valor, na perspectiva marxista, deixa de operar na sua plenitude. Nessa situação, onde as condições endógenas de reprodução do sistema deixam de existir, torna-se necessária a intervenção do Estado para garanti-las e impedir sua derrocada 5 .

iv. A crise do Estado do bem-estar (estagflação associada à dificuldade financeira do Estado), nos anos 60 e 70, desencadearam a ideia

\footnotetext{
3Para compreender a fraqueza de a burguesia nascente ver Engels (2010) "A revolução antes da revolução" e Huberman (1979) "História da Riqueza do Homem".

${ }^{4}$ IDEM

Para Keynes, a entrada em cena do Estado, por meio da implementação de políticas indutoras de investimento e geradoras de renda e emprego, combinadas com políticas de conteúdo redistributivo, torna-se uma exigência para evitar as força e entodestrutivas do mercado conduzam o sistema para o colapso. Assim, dotando o Esado le políticas de estabizacão voltas perã

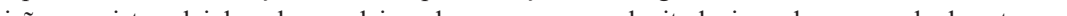
visão marxista, a lei do valor, ao deixar de operar na sua plenitude, impede o mercado de autorregular e garanti a reprodução do sistema, o que leva o Estado a assumir e desempenhar as funções de acumulação e legitimação para garantir essa reprodução (apud OLIVEIRA, 2012).
}

força do pensamento neoliberal, que passou atribuir ao Estado a responsabilidade pelos desiquilíbrios do sistema e a sugerir como saída da crise, o esvaziamento de suas funções. Entretanto, nas décadas seguintes, os resultados colhidos com as propostas de encolhimento levaram o pensamento dominante a uma revisão, já que o Estado é necessário para garantir a reprodução do sistema, à medida que o mercado não dispõe de mecanismo para tanto. Deve-se portanto procurar reciclar e regular suas instituições, capacitando-o a melhor desempenhar suas funções com maior eficiência e a um custo mais baixo para a sociedade e o capitalismo: questões propostas nas teorias Neoinstitucionalistas, Nova Economia Política, que dão respaldo às propostas do Estado gerencial, que opera com eficiência. As crises do final do século XX e primórdios do XXI reforça as teorias institucinalistas de regulação do mercado.

Desse quadro temporal da trajetória do Estado fica evidenciado que: (i) o papel desempenhado pelo Estado capitalista tem uma determinação histórica, que só pode ser entendida no contexto das necessidades e crises do sistema e das condições exigidas para reprodução; (ii) nos momentos em que o mercado se mostrou incapaz de garantir, endogenamente, essas condições, o Estado foi convocado para desempenha-las, politizando a economia, ao trazer para seu seio a regulação dos conflitos entre classes e suas frações (OLIVEIRA, 2012).

O aumento crescente de seu papel na economia, como resultado desse processo, terminou conduzindo-o a um forte desiquilíbrio financeiro, que passou a ser identificado como causa primária da crise de sistema, cuja remoção se torna indispensável, na visão liberal, para restaurar as suas forças recuperar sua eficiência. Na visão keynesiana, assim como na visão marxista, o Estado aparece como vital para assegurar a reprodução do sistema. Na keynesiana, o cumprimento pelo Estado das funções distributiva e estabilizadora é indispensável para amortecer as flutuações cíclicas do sistema e garantir sua reprodução. Por outro lado, na marxista, a necessidade de o Estado atuar como agente de acumulação e legitimação torna visível a sua essência, a simbiose que estabelece com capital, a sua construção - e transformações em ossatura material e suas formas de intervenção - de acordo com as exigências políticas e/ou econômicas surgidas nas diversas fases de desenvolvimento do capitalismo (apud OLIVEIRA, 2012). 
O Estado contemporâneo está fortemente orientado para a construção interna das condições de existência de seu próprio território. Isso vai propor então, uma série de caminhos de desenvolvimento de um Estado que o colocará em confronto com sua própria natureza de Estado monopolista da violência, da legitimidade e, portanto, da representação, no sentido mais moderno, dessas populações. É o Estado que constrói a existência da Nação, que apresenta esse sentido de nacionalidade e de melhorar as condições de existência dessa sociedade - ele leva à construção de uma estrutura política e administrativa, que começa a estabelecer uma série de atividades que não estavam dadas pela matriz original do Estado moderno. Um dos grandes paradoxos da modernidade é que os Estados que são construídos como máquinas eficazes de dominação das sociedades acabam sendo aprisionados pelo processo de desenvolvimento destas mesmas sociedades. Isso tem implicações nas políticas públicas (COSTA, 2105).

O Estado contemporâneo é, por natureza (histórica), o Estado das Políticas Públicas. As políticas públicas que estão sendo construídas também refletem a natureza dos conflitos e a dinâmica dessa dupla natureza do Estado; a qual se estrutura através do monopólio do poder, mas ao mesmo tempo representa as diversidades e desigualdades da sociedade. A pluralidade constitui-se num único e mesmo processo histórico. As políticas públicas são a expressão dessa contradição. Isto porque se conforma como um espaço de expressão dos interesses mais diversos da sociedade; contudo estão estruturadas no aparato de Estado, que tem características concentradoras de poder e, por vezes violento. Esse conflito vai aparecer durante todo o processo de formulação e implementação das políticas públicas. As Políticas Públicas, portanto, refletem a heterogeneidade da sociedade capitalista e suas contradições (COSTA, 2015).

Assim, cada Estado nacional tem uma história própria, que traz consigo contornos de processos de diferentes realidades culturais, econômicas, sociais e a história revela a identidade de cada sociedade.

Tentando resumidamente situar a trajetória brasileira no campo das relações entre Estado e politicas publicas, Oliveira (2012) destaca três períodos. O primeiro, que se estende até a década de 1930, apresenta as características de um Estado ${ }^{6}$ de cunho liberal, restringindo suas atividades, até mesmo pelas limitações financeiras, a episódicas e localizadas incursões nas atividades econômicas do país. Do ponto de vista da política

\footnotetext{
${ }^{6}$ Ver FURTADO (1986) “Análise do Modelo Brasileiro".
}

econômica, contudo, sob o controle das oligarquias é um Estado com forte poder regulatório, que intervém expressivamente na atividade econômica, principalmente pela adoção de medidas protecionistas voltadas a defender os níveis de produção e de renda dessas mesmas oligarquias, ou seja, do setor hegemônico da economia.

O segundo que se inicia nos anos trinta e se prolonga até o início dos anos 1980, um Estado ${ }^{7}$ que deu início, avançou e consolidou suas bases materiais e institucionais, libertando-se dos interesses oligárquicos imediatos e colocando-se em condições de atuar como um Estado moderno, capitalista e de implementar políticas no âmbito nacional. Nesse período é um Estado que se caracteriza por forte envolvimento, intervencionismo e regulação em vários campos da vida econômica e social - educacional, trabalhista, previdenciário, entre outros. O Estado atuou como indutor, organizador e agente estruturante do desenvolvimento capitalista nacional, com forte atuação na constituição de suas bases, por meio das empresas estatais, dos investimentos públicos e sociais, e da implementação de políticas voltadas para estimular o investimento privado. O modelo de Estado que surgiu deste paradigma passou a assentar-se no compromisso de ampliação dos espaços para garantir a soberania do mercado. Estado de vertente keynesiana/cepalina.

Um terceiro que tem início, nos anos 1980, revela um Estado em crise, mergulhado numa profunda crise fiscal, questionado em sua dimensão e eficiência pelas mesmas elites que se beneficiaram enquanto vigorou o desenvolvimento anterior. Por essa razão, o Estado que começou a ser reconstruído neste período, no Brasil, seguiu as recomendações preconizadas pela doutrina neoliberal, consubstanciadas nos postulados do Consenso de Washington ${ }^{8}$, o que significou promover reformas para sua retirada da vida econômica.

A retirada do Estado da economia significou mudança em sua ossatura material, com a adoção de políticas de abertura comercial e financeira, desregulamentação da economia e de desmonte do setor público e das políticas sociais. De modo geral, privatizando empresas estatais e promovendo/reduzindo o compromisso com a oferta de política pública, em prol das forças de mercado. Ao mesmo tempo em que se encaminhara uma série de reformas para realizar seu ajustamento financeiro e assegurar

${ }^{7}$ Ver CARDOSO DE MELLO (1982) “Capitalismo Tardio: contribuição crítica da formação e desenvolvimento

da economia brasileira".
"Ver Paulo Nogueira Batista "Consenso de Washington: a visão neoliberal dos problemas latino-americanos (1994). Disponível em http://www.consultapopular.org.br/sites/default/files/consenso $\% 20 \mathrm{de} \% 20$ washington.pdf. 
uma gestão responsável de suas finanças, traduzida em equilíbrio fiscal e garantia de sustentabilidade e pagamento da dívida pública e de seus encargos (OLIVEIRA, 2012).

A remodelagem da ossatura material do Estado, em nome da eficiência e eficácia, bem com a limitação de seu papel regulador, refletem as exigências colocadas pelo capitalismo nestes tempos de globalização, em que o afastamento do Estada regulação de mercado é pelo capital considerado essencial para garantir seu curso natural, sem incorrer em ônus excessivo representado pela necessidade de manter o apoio e coesão das classes dominadas, por meio de políticas redistributivas, que drenam parcela substancial de seus ganhos (OLIVEIRA, 2012).

Uma característica desse Estado contemporâneo é que não existe mais limite para a definição de uma agenda de políticas públicas. (COSTA, 2015). A Política Pública tem sua origem nos meados século XX, quando o Estado se vê confrontado com uma série de desafios econômicos e sociais. O que faz com que o Estado se confronte com os problemas nacionais e se volte para o desenvolvimento do país. Portanto, a natureza das Políticas Públicas se insere em uma agenda de ação advinda do Estado. Neste caso, podem se desdobrar em qualquer campo de atividade, desde que essa atividade seja de intervenção estatal.

Desde Constituição de 1988 tem sido institucionalizada o a produção de políticas públicas, conceito que engloba as políticas sociais. Trouxe-se à tona a ideia da política social como instrumento de inclusão social; nesse contexto, estão associadas ao resgate da cidadania e de sua universalização.

Tomando como referência o trabalho de Theodoro e Delgado (2003), as políticas sociais podem ser compostas por um conjunto de programas e ações de garantia de direitos, que vão desde políticas estruturadas no aparelho estatal (saúde, educação, seguridade social, entre outras) até as de caráter emergencial no atendimento a uma demanda difusa (atendimento a questões emergenciais, efêmeras) passando pelas de caráter temporal. As políticas sociais temporárias são aquelas que também respondem pela garantia dos direitos sociais previstos no ordenamento constitucional, mas que, diferentemente do primeiro grupo, dependem da iniciativa dos governos por meio de ações e programas temporais para que os cidadãos possam exercitar os direitos ali designados; entretanto seus recursos orçamentários em geral estão vinculados constitucionalmente, mas não estão protegidos de cortes como as do primeiro grupo.
No caso do SISAN (políticas sociais temporárias), no período de 2003 a 2016, a resolução da questão alimentar passou pela ação de Estado, com formulação e execução políticas sociais, ou seja, atos de governo que determinaram um padrão de proteção social: direitos sociais e dever do Estado; universalidade do acesso; instrumentos de inclusão social; e alocação de recursos, bens e serviços públicos. A governança dessas políticas sociais teve ênfase nas formas de participação da sociedade civil num contexto de descentralização federativa, ou seja, de interação Estado e sociedade civil em todos os níveis federativos (União, estados, municípios e distrito federal).

\section{SISAN: conjunção do estado e sociedade civil}

Em 2003, logo no início do mandato, Luiz Inácio Lula da Silva definiu a estratégia "FOME ZERO" como umas de suas prioridades nas políticas sociais de governo. Essa estratégia compôs um rol de políticas e programas fins de resolução da Questão Alimentar nacional: disponibilidade de alimento e água, acesso aos alimentos, consumo de alimentos prejudiciais à saúde e a falta de conformidade na oferta e consumo acessível desses alimentos (BELIK, 2014). E traçou um leque de ações voltado a assegurar o Direito Humano à Alimentação Adequada (DHAA) às pessoas, a partir de quatro eixos articuladores: acesso aos alimentos, fortalecimento da agricultura familiar, geração de renda e articulação, mobilização e controle social (MACEDO et ali, 2009).

Para condução institucional dessa estratégia criou um ministério específico ${ }^{9}$, e recriou o Conselho de Segurança Alimentar e Nutricional (CONSEA $)^{10}$ com ampla participação social ${ }^{11}$. Assim, buscou centralidade compartilhada entre Estado e sociedade civil na formulação e monitoramento das políticas públicas de Segurança Alimentar e Nutricional (SAN). Para a institucionalização de um espaço comum de construção de senso comum governo e sociedade civil foi designado ao CONSEA a realização de Conferencias Nacionais de Segurança Alimentar e Nutricional (CNSAN).

Assim, nesse contexto compartilhado Estado e sociedade civil se compôs

\footnotetext{
${ }^{9}$ Ministério Extraordinário da Segurança Alimentar (MESA), posteriormente, com a extinção do mesmo, foi conduzida pelo Ministério do Desenvolvimento Social e Combate à Fome (MDS).

${ }^{10} \mathrm{Em} 1993$ foi CONSEA, sendo que em 1994 foi constituída a primeira Conferência Nacional de Segurança Alimentar - CNSA. A experiência do CONSEA foi interrompida após dois anos de execução, em 1995, no governo Fernando Henrique Cardoso (MACEDO et ali, 2009).

governo Fernando Henrique Cardoso (MACEDO et ali, 2009).
"Disposto no organograma de governo, diretamente ligado ao gabinete da Presidência da República, com o seu presidente escolhido pela sociedade civil.
} 
um conjunto de políticas sociais e um arcabouço de normas e leis de SAN (legislação constitucional e ordinária em vigor ${ }^{12}$ ), que atribuíram ao Estado à responsabilidade das questões: direito humano a alimentação adequada (DHAA), produção de alimentos (tendo como prioridade a agricultura familiar) e abastecimento alimentar (distribuição e acesso ao alimento, principalmente, a população em risco alimentar).

A promulgação da Lei n ${ }^{0} 11.346 / 2006^{13}$ estruturou o Sistema Nacional de Segurança Alimentar e Nutricional (SISAN), com vistas assegurar a implantação e consolidação das políticas públicas de SAN no território nacional. Como estabeleceu o conceito nacional de SAN: visava garantir que todos tenham o direito a uma alimentação saudável, acessível e de qualidade, em quantidade suficiente de modo permanente sem comprometer o acesso a outras necessidades essenciais; tendo como base práticas alimentares promotoras da saúde e de respeito a diversidade cultural e, ambientalmente e socialmente sustentáveis; ou seja, garantir o direito do brasileiro de se alimentar devidamente, segundo as particularidades e características socioculturais de cada região (CONSEA, 2007).

As diretrizes nacionais de SAN tiveram um caráter de equidade social, com o trinômio: produção de alimentos, abastecimento alimentar/consumo alimentar e conservação ambiental, assentado nos eixos ${ }^{14}$ (CONSEA, 2007): (i) ampliação das condições de acesso; (ii) conservação da biodiversidade e utilização sustentável dos recursos ambientais; (iii) promoção da saúde, da nutrição e da alimentação da população, em especial de populações em situação de vulnerabilidade social; (iv) garantia da qualidade biológica, sanitária, nutricional e tecnológica dos alimentos; (v) implementação de políticas públicas e estratégias sustentáveis e participativas de produção, comercialização e consumo de alimentos, respeitando-se as múltiplas características culturais do País.

O SISAN conta com duas instâncias: o CONSEA e a Câmara Interministerial de Segurança Alimentar e Nutricional (CAISAN). Durante os governos de Lula e Dilma o CAISAN foi presidido pelo MDS (Ministério

\footnotetext{
${ }^{2} \mathrm{O}$ direito à alimentação foi incorporado à legislação nacional quando da ratificação do Pacto Internacional de Direitos Humanos Econômicos, Sociais e Culturais em julho de 1992 sob a forma de Decreto Legislativo ${ }^{\circ}$ 591(MACEDO et ali, 2009)

${ }^{3}$ Lei disponível em https://www.planalto.gov.br/ccivil_03/_ato2004-2006/2006/lei/111346.htm.

${ }^{14}$ Artigo $4^{\circ}$ da Lei 11.346/2006.
}

o Desenvolvimento Social), tendo representação de vários Ministérios ${ }^{15}$.

Coube a CAISAN articular e coordenar a Política Nacional de SAN. Esse sistema foi sendo distribuído pelo país ao articular: (i) as Conferências de Segurança Alimentar e Nutricional, em âmbito federativo (União, estados e municípios); (ii) os Conselhos de Segurança Alimentar e Nutricional (CONSEA), de caráter federativo; (iii) a Câmara Interministerial (âmbito nacional) e as Câmaras Intersetoriais de SAN dos outros entes federativos (CAISAN); (iv) os órgãos ou entidades de SAN da União e dos estados, Distrito Federal e municípios; (v) as instituições privadas, com ou sem fins lucrativos, que manifestassem interesse de adesão e que respeitem os critérios, princípios e diretrizes do SISAN.

O Decreto n. ${ }^{\circ}$ 7272/2010 edificou as diretrizes da Política Nacional de SAN (PNSAN), e fixou os parâmetros para a elaboração do Plano Nacional de Segurança Alimentar e Nutricional (PLANSAN), principal instrumento de planejamento, gestão e execução de política pública de SAN no território nacional. O $1^{\circ}$ PLANSAN (2012/2015) compôs diversas iniciativas dos Ministérios membros, ao agregar dezenas de ações e programas articuladas nas diretivas, dentre as quais destaca-se: (i) promoção do abastecimento e da estruturação de sistemas descentralizados; (ii) acesso à alimentação adequada e à água; (iii) instituição de processos permanentes de educação alimentar e nutricional; (iv) fortalecimento da agricultura familiar; (v) abastecimento alimentar; (v) fortalecimento das ações de alimentação e nutrição em todos os níveis de atenção à saúde; (vi) promoção ao direito da alimentação saudável e adequada; bem como, ações de abastecimento e de produção alimentar direcionadas aos povos indígenas, quilombolas e demais povos e comunidades tradicionais. Ao término do quatriênio do $1^{\circ}$ PLANSAN foi proposto o segundo, que, praticamente, seguiu as mesmas diretivas (CAISAN, 2011).

SISAN: ações, participação e redes de politicas publicas

O SISAN instaurou ações de abastecimento alimentar (tendo como prioridade as pessoas em situação de vulnerabilidade social) e de fomento

${ }^{15}$ Compõem a CAISAN: Casa Civil; Secretaria-Geral da Presidência; Desenvolvimento Social (MDS); Agricultura, Pecuária e Abastecimento (MAPA); Ciência, Tecnologia e Inovação (MCTI); Desenvolvimento Agrário (MDA); Educação (MEC); Saúde (MS); Fazenda (MF); Justiça (MJ); Meio Ambiente (MMA); Pesca e Aquicultura (MPA); Integração, Cidades (MCidades); Secretaria de Políticas para as Mulheres (SPM); Secretaria de Direitos Humanos (SDH); Relações Exteriores (MRE); Secretaria de Políticas de Promoção da Igualdade Racial (SEPPIR) e Planejamento, Orçamento e Gestão (MP) e Trabalho e Emprego (MTE) 
à produção agrícola familiar pelo território nacional. Os meios e fins dessas ações foram sendo definidos tanto pelo preceito normativo legal, quanto pelas esferas federativas de governo e comunidades de atores sociais fins (beneficiados pelos programas), como também, pela sociedade ${ }^{16}$. Esse arranjo nacional e territorial de elaboração e execução de políticas públicas de SAN compreendeu alguns elementos de governança. Do ponto de vista institucional da gestão foi idealizado quanto princípios a intersetorialidade e a participação social, previstos nos Artigos $8^{\circ}$ e $9^{\circ}$ da Lei 11.346/2006 ${ }^{17}$.

A intersetorialidade significou edificar no governo (CONSEA, 2007) ações planejadas e executadas de forma partilhada entre setores do governo federal, dispondo os orçamentos fins a atender as prioridades definidas em conjunto; atuação federativa de promoção de segurança alimentar e nutricional e de garantia do Direito Humano à Alimentação Adequada (DHAA) e fomento a agricultura familiar. O que significou consagrar um conteúdo transversal e de integração, envolvendo vários ministérios nos programas de SAN, como também, compartilhar a gestão dos programas de SAN com estados, municípios e ao distrito, ao delegar atribuições. A descentralização federativa implicou numa tentativa de regionalização, quer dizer, levar a governança para âmbito local.

A participação social foi um propósito cotidiano de articulação de um diálogo e construção do senso comum entre o Estado e sociedade civil nas etapas de formulação, planejamento e avaliação das políticas públicas de SAN.

Segundo o CONSEA (2007), através da consolidação nacional e local do SISAN, o governo e sociedade civil cooperaram na elaboração, em alguns casos na execução, de políticas e ações de combate à fome, de fomento à produção agrícola familiar e de promoção da segurança alimentar da nação. Também houve cooperação da sociedade civil tanto no monitoramento delas e quanto formulação legal dos parâmetros da segurança alimentar nacional, segundo os princípios e diretrizes definidas a partir de critérios estabelecidos pelo CONSEA e pela CAISAN.

\footnotetext{
${ }^{16}$ Os entes federativos (Estados, Municípios e o Distrito federal) para aderirem ao SISAN tiveram que assumir o compromisso de elaborar seus planos de segurança alimentar e nutricional próprios, por um processo que compreendesse a participação de gestores públicos e sociedade civil, segundo o seu contexto socioeconômico e territorial; no limite do marco regulatório nacional e local.

${ }^{17}$ Segundo o documento referência da $5^{\text {a }}$ Conferência Nacional de Segurança Alimentar e Nutricional Documento disponível em www4.planalto.gov.br/consea/eventos/conferencias/ $/ 5$ a-conferencia-nacional-de-seguran-

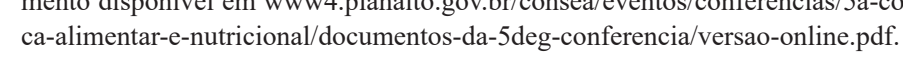

Como elemento constitutivo do SISAN, a participação social consagrou sua cooperação através do CONSEA (nacional, estadual, municipal e do distrito federal) e da Conferência de SAN (dos entes federativos).

Neste campo institucional aconteceram as mediações de promulgação de normas e, de formulação, avaliação e monitoramento dos programas de governo. Conformaram-se espaços públicos por onde se estabeleceu o binômio conflito e acordo dos diversos interesses entre sociedade civil e governo, lócus de exercícios de consenso. Ou seja, se instituiu uma política de Arena (no sentido dado por FREY, 1999; GRISA, 2011).

Por determinação de governo houve fortalecimento do tecido social no espaço de Estado, o qual, por sua vez, passou a tratar a sua cooperação nesta esfera institucional na forma de redes de ação pública.

Nas redes de ação pública, segundo MASSADIER (2006) destacam-se os processos de intermediação de grupos de interesses, onde os atores sociais convergem numa racionalidade do tipo convencional, participando dela para compartilhar recursos e também ideias.

Além deste arranjo de Arena e Redes de Ação Pública, em alguns programas de governo foi delegada para algumas instituições sociais uma série de programas públicos, através de contratação por convênios ou outras formas de contrato de gestão, no sentido se acolher uma demanda específica num processo de parceria público-social. Como por exemplo, no caso do Programa de Aquisição de Alimentos da agricultura familiar (PAA), cooperativas de produtores agrícolas familiares foram executores dele.

Como disse Poulantzas (1980), o Estado age de forma positiva e não somente sob o ângulo exaustivo da repressão e da doutrinação de classe, contudo estes aspectos existem na materialidade das funções do Estado; entretanto, a relação das classes dominadas com o poder e o Estado, no que se chama de consenso, possui um substrato material: medidas de governo que refletem concessão impostas pelas lutas delas.

O espaço de cooperação de arenas foi também ambiente de pressão social a infligir ao Estado obrigações ao decidido. $\mathrm{O}$ documento $5^{\text {a }}$ Conferência Nacional de Segurança Alimentar e Nutricional: "Comida de Verdade no Campo e na Cidade" ${ }^{18}$ (pag. 39) expõe a ausência ou não obrigatoriedade de retorno ou aplicação das recomendações ou deliberações dos órgãos

Segundo o documento referência da 5 a Conferência Nacional de Segurança Alimentar e Nutricional Documento disponível em www4.planalto.gov.br/consea/eventos/conferencias/5a-conferencia-nacional-de-segurancaalimentar-e-nutricional/documentos-da-5deg-conferencia. 
colegiados nas políticas públicas do Poder Executivo, com pouco diálogo no Poder Legislativo e quase nenhuma incidência no judiciário.

Quer dizer, o espaço institucional de cooperação, também foi por onde se percebeu os limites da ação social nas ações de Estado, ao reconhecer suas desigualdades de poder existentes no interior do círculo de governo.

Nesta direção, como mostrou Offe $(1984$, p. 85), à medida que se colocam processos consensuais delineiam-se riscos tendo em vista heterogeneidade de interesses: as estruturas de poder e interesses econômicos que podem ser obstáculos à realização dos programas; e a automatização de processos de consenso que sujeitam premissas que sobrecarregam o governo.

\section{SISAN: fomento à agricultura familiar.}

Na prática cotidiana do SISAN também se pode observar que houve programas e ações de convergência para inserção socioeconômica do diverso tecido social da agricultura familiar ${ }^{19}$ como mostra o documento de

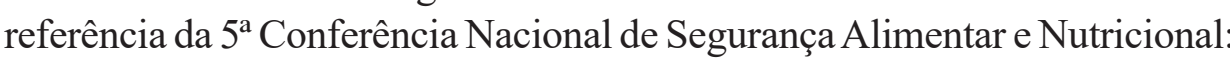
"Comida de Verdade no Campo e na Cidade ${ }^{20 "}$ e o do $2^{\circ}$ Plano Nacional de Segurança Alimentar e Nutricional (PLANSAN) ${ }^{21}$. Nele se destacou o papel da Agricultura Familiar na alimentação dos brasileiros.

E neste contexto, esta Conferência, reiterou ${ }^{22}$ a importância do fortalecimento das diversas políticas públicas para este setor rural: (i) de crédito; (ii) de assistência técnica e extensão rural; (iii) de apoio à comercialização; (iv) de proteção da produção; (v) da renda; (vi) de inclusão social.

Cabe lembrar ainda, que os documentos citados acima, também reafirmaram os temas relacionados: (i) à diversidade cultural e territorial; (ii) a sustentabilidade ambiental; (iii) a reforma agrária; (iv) a regularização fundiária de posseiros, quilombolas e indígenas.

A agricultura familiar foi envolvida pelo SISAN com ações de fomento

\footnotetext{
${ }^{19} \mathrm{~A}$ agricultura familiar no plano institucional de governo se conformou numa categoria social com diferentes processos sociais constitutivos tanto em relação à terra (proprietário, posseiro, quilombolas, indígenas; extrativistas e pescadores artesanais) quanto na condição do produtor (patronal e não patronal) - Lei $n^{\circ} 1.1326 / 2006$, artigo $3^{\circ}$ (SILVA, et ali, 2014).

${ }^{20}$ Documento disponível em http://www4.planalto.gov.br/consea/eventos/conferencias/5a-conferencia-nacionalde-seguranca-alimentar-e-nutricional/documentos-da-5deg-conferencia/versao-online.pdf

${ }^{21}$ Documento disponível em http://www4.planalto.gov.br/CONSEA/comunicacao/noticias/plano-nacional-deseguranca-alimentar-e-nutricional-ja-esta-disponivel-na-internet.

seguranca-alimentar-e-nutricional-ja-esta-disponivel-na-internet. ${ }^{22}$ Visto que tal tema está expresso em todos os documentos públicos do CONSEA, CAISAN, CNSAN e PLANSAN
valorizando a diversidade social, cultural, territorial, ambiental e a pluralidade econômica do rural brasileiro
}

produtivo e de abastecimento alimentar a fim de garantir a estabilidade desse produtor, principalmente, na distribuição de alimentos à população em situação de vulnerabilidade social. Dentre os programas alinhavados no SISAN, se destaca o PAA $^{23}$ (Programa de Aquisição de Alimentos da Agricultura Familiar), pela sua temporalidade.

O PAA se caracteriza como exemplo de programa intersetorial para fomento à agricultura familiar, ao constituir approach de programas que viabilizaram tanto a oferta de alimentos proveniente da agricultura familiar para a demanda por alimentos de populações em situação de insegurança alimentar; equipamentos públicos (alimentação escolar, hospitais, distribuição gratuita de alimentos, presídios, etc.); como também, de formação de estoques.

Assim, ao conectar o modo familiar de produção de alimentos aos padrões de consumo e hábito alimentar nacional; foram também assinalados os direitos a terra, a água, aos recursos naturais e de reconhecimento da produção familiar na economia agrícola como elementos decisivos para estratégia de implantação do SISAN.

Em resumo, SISAN requereu interações e cooperação entre instituições públicas e destas com a sociedade civil, formando espaços compartilhados para se formular e executar serviços e bens públicos de abastecimento alimentar para habilitação de pessoas em situação de vulnerabilidade social e desenvolvimento da agricultura familiar.

SISAN: resultados expressivos na distribuição da renda As ações de Estado foram direcionadas rumo à lógica compartilhada governo e sociedade civil a partir de processos concomitantes. Com multiplicação de modos e locais de interação dos agentes públicos com os atores sociais (Arenas, Redes), o governo passou, atuar tanto nas repartições que gerencia como no aspecto de cooperação público-social.

$\mathrm{O}$ ato do Estado situou em múltiplos espaços o exercício compartilhado de mediação; que envolveu desde negociação de interesses de classes e grupos sociais subalternos até o acesso a bens e serviços públicos, como a execução de algumas funções públicas (por exemplo, o PAA que em alguns momentos foi executado por organizações de produtores familiares).

Para aquisição dos alimentos de agricultores familiares o governo contou tanto com a estrutura federativa da CONAB (Companhia Nacional de Abastecimento) quanto do apoio operacional de estados e municípios. 
Tal esforço de governo de construção do SISAN, conjugado com as políticas de distribuição de renda ${ }^{24}$, trouxe resultados na diminuição da desigualdade social e na erradicação da fome - entre 2004 e 2014 o número de domicílios em situação de Segurança Alimentar ${ }^{25}$, cresceu de $68,1 \%$ para 77,4\% (PNAD, 2014).

Ao longo da década a desigualdade de renda diminuiu substancialmente, entre 2001 a 2014, o Índice de Gini do rendimento de trabalho diminuiu continuamente, de 0,563 para 0,489. Apesar desta tendência de queda permaneceu elevada a desigualdade, no que diz respeito à renda o país se classifica entre os quinze piores do mundo (PNUD 2015; OCDE, 2015).

No mesmo período aconteceu também uma elevação significativa do $\mathrm{IDH}^{26}$ (Índice de Desenvolvimento Humano), de 0,683 em 2000 para 0,755 em 2014, passando da faixa de países de IDH-médio para IDH-alto ${ }^{27}$, com uma taxa média de crescimento anual de $0,96 \%$. Porém, no período, esta taxa teve um comportamento díspar ao se comparar as três últimas décadas: era de $1,18 \%$ no período entre 1990 e 2000 ; caiu para $0,76 \%$ entre 2000 e 2010; e para 0,60\% entre 2010 e 2014; apontando uma inflexão no ritmo de evolução dos três índices que compõem o IDH (saúde, educação e renda) no país (PNUD, 2015).

$\mathrm{Na}$ trajetória da formulação das politicas relacionadas ao SISAN se destacam três eixos de intervenção que obtiveram resultados expressivos:

1) Programas de abastecimento alimentar que proporcionaram o acesso alimentar a populações em situação de vulnerabilidade social, por exemplo: a) PNAE $^{28}$ (Programa de Alimentação Escolar), os recursos orçamentários disponibilizados para tiveram uma taxa de crescimento anual na ordem de $22,2 \%$ e número de alunos atendidos

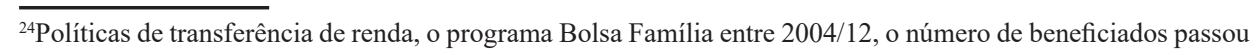
de 6,6 para 13,9 milhões.

${ }^{25}$ Segundo a PNAD (2014) domicílios em Segurança Alimentar: aqueles que têm acesso regular e permanente a alimentos de qualidade.

a alimentos de qualidade.
${ }^{26} \mathrm{O}$ objetivo da criação do Índice de Desenvolvimento Humano foi o de oferecer um contraponto a outro indicador muito utilizado, o Produto Interno Bruto (PIB) per capita, que considera apenas a dimensão econômica do desenvolvimento. Criado por Mahbub ul Haq com a colaboração do economista indiano Amartya Sen, ganhador do Prêmio Nobel de Economia de 1998, o IDH pretende ser uma medida geral, sintética, do desenvolvimento humano. Disponível em http://www.pnud.org.br/IDH/.

${ }^{27} \mathrm{O}$ IDHM é um número que varia entre 0 e 1 , quanto mais próximo de 1 , maior o desenvolvimento humano. A faixas de IDH: até 0,499 IDH-baixo; de 0,500 a 0,699 IDH-médio; de 0,700 a 0,799 IDH-alto; e acima de 0,800 IDH-muito alto. Disponível em http://www.pnud.org.br/IDH/

${ }^{28}$ Dados do FNDE, disponível em http://www.fnde.gov.br/programas/alimentacao-escolar/alimentacao-escolarconsultas/alimentacao-escolar-dados-f\%C3\%ADsicos-e-financeiros-do-pnae. passou de 37,8 para 41,5 milhões, entre 2004/15; b) Doação Simultânea de Alimentos do PAA ${ }^{29}$ (Programa de Aquisição de Alimentos da Agricultura Familiar) 10,9 milhões de pessoas em situação de vulnerabilidade social receberam alimentos, entre 2005/15

2) Programas de transferência de renda conjugado as políticas de emprego e renda possibilitaram alavancar o poder aquisitivo das famílias pobres, consequentemente, melhorar o acesso delas ao abastecimento alimentar, por exemplo: a) O programa Bolsa Família ${ }^{30}$ entre 2004/12, o número de beneficiados passou de 6,6 para 13,9 milhões; b) Políticas de emprego ${ }^{31}$, entre 2004/14 a taxa de desemprego caiu de $9,7 \%$ para $7,5 \%$, no período $2004 / 14$ e houve crescimento do salário mínimo ${ }^{32}$ com incremento na de $16 \%$ ao ano; (c) Renda ${ }^{33}$, a renda média de todos os trabalhadores no período de $2004 / 14$ passou de $\mathrm{R} \$ 1.035,61$ para $1.737,13$.

Entre 2004/14 a taxa de desemprego caiu de $9,7 \%$ para $7,5 \%$, no período 2004/14 e houve crescimento do salário mínimo ${ }^{34}$ com incremento na de 16\% ao ano; (c) Renda ${ }^{35}$, a renda média de todos os trabalhadores no período de 2004/14 passou de $\mathrm{R} \$ 1035,61$ para 1737,13 . (FONTE)

${ }^{29}$ Dados da CONAB, disponível em http://www.conab.gov.br/conteudos.php?a=1402\&t=2, e os dados do IPEAdata, disponível em www.ipeadat.gov.bi

${ }^{30} \mathrm{O}$ Bolsa Família é um programa de transferência de renda com condicionalidades, focalizado em famílias pobres cadastradas em cada município do país. Resultante da unificação de diferentes programas, foi instituído por lei em 2004. O valor do benefício, reajustável por decreto, varia conforme a renda domiciliar per capita da família, o número e a idade dos filhos (IPEAdata).

${ }^{31}$ Segundo dados do IPEAdata, disponível em www.ipeadat.gov.br/.

${ }^{32}$ Desde 2007 o reajuste do SM deveria repor a inflação mais o crescimento do PIB de dois anos antes. Ta procedimento virou Lei 12382/2011, que vigorou até 2015, a qual trouxe previsibilidade de formulação de projeto de Lei para o reajuste dos anos seguintes. Disponível em http://www.planalto.gov.br/ccivil_03/_Ato20112014/2011/Lei/L12382.htm.

${ }^{33}$ Segundo dados do IPEAdata, disponível em www.ipeadat.gov.br/. Média, por pessoa ocupada, dos rendimentos mensais brutos totais em dinheiro recebidos em todos os trabalhos no mês de referência da Pesquisa Nacional por Amostra de Domicílios (PNAD/IBGE). Valores reais expressos aos preços vigentes no mês de referência da última Pnad disponível, calculados a partir dos microdados da pesquisa e atualizados conforme o deflator para rendimentos da Pnad apresentado pelo IPEAdata. Elaboração: DISOC/IPEA

${ }^{34}$ Desde 2007 o reajuste do SM deveria repor a inflação mais o crescimento do PIB de dois anos antes. Tal procedimento virou Lei 12382/2011, que vigorou até 2015, a qual trouxe previsibilidade de formulação de projeto de Lei para o reajuste dos anos seguintes. Disponível em http://www.planalto.gov.br/ccivil_03/_Ato20112014/2011/Lei/L12382.htm.

${ }^{35}$ Segundo dados do IPEAdata, disponível em www.ipeadat.gov.br/. Média, por pessoa ocupada, dos rendimentos mensais brutos totais em dinheiro recebidos em todos os trabalhos no mês de referência da Pesquisa Nacional por Amostra de Domicílios (PNAD/IBGE). Valores reais expressos aos preços vigentes no mês de referência da por Amostra de Domicilios (PNAD/IBGE). Valores reais expressos aos preços vigentes no mês de referência da
última Pnad disponível, calculados a partir dos microdados da pesquisa e atualizados conforme o deflator para rendimentos da Pnad apresentado pelo IPEAdata. Elaboração: DISOC/IPEA 
Dentre os programas bem-sucedidos cabe destacar os programas de fortalecimento da agricultura familiar no campo do abastecimento alimentar nacional, por exemplo, o PAA, que entre 2003/15 disponibilizou R \$ 3,4 bilhões na aquisição de 219,7 mil toneladas de alimentos, sendo que, cerca de um total de 95,7 mil produtores venderam seus $\operatorname{produtos}^{36}$ (que significa $22 \%$ do total de agricultores familiares registrado pelo Censo Agropecuário de 2006/IBGE participaram deste programa).

No campo da produção de alimentos e de abastecimento alimentar a fim de garantir a estabilidade na distribuição de alimentos à população em situação de vulnerabilidade social, os recursos do PAA, entre 2010 a 2015, operacionalizados pela $\mathrm{CONAB}$ totalizou $\mathrm{R} \$ 2,3$ bilhões. No período, foram adquiridos 1,2 milhões de toneladas de diversos produtos, beneficiando em média por ano 77 mil produtores familiares ${ }^{37}$.

Esse esforço foi ancorado com a evolução do volume de recursos orçamentários aportados nessas políticas sociais; por exemplo, as estatísticas compiladas pelo CONSEA e pelo Instituto de Estudos Socioeconômicos (INESC) demonstraram que o orçamento para programas de SAN (em valores reais de agosto de 2011) saltou de $\mathrm{R} \$ 11,1$ bilhões para $\mathrm{R} \$ 28,5$ bilhões, entre 2004 e 2011 (BELIK, 2014).

Segundo a $\mathrm{CONAB}^{38}$, no ano 2015, a renda média dos 38,8 mil agricultores familiares que participaram do PAA foi de $\mathrm{R} \$ 7.411,33$, o que equivale a um aumento de $375 \%$ quando comparado à renda média no ano de 2003 (R\$ 1.972,41).

$\mathrm{O}$ arranjo institucional de políticas de crescimento econômico e de combate à pobreza, por meio de programas de transferências de renda condicionadas; de acesso ao alimento; de emprego e renda; e de inserção produtiva da agricultura familiar, permitiu uma melhora no poder aquisitivo da população; alavancando o consumo das classes populares e transformando esse aumento real no motor de um círculo virtuoso de crescimento econômico do país.

\section{SISAN: a inflexão da estratégia fome zero}

Apesar dos avanços institucionais e sociais obtidos, os dados da Pesquisa

${ }^{36}$ Dados da CONAB, disponível em http://www.conab.gov.br/conteudos.php?a=1402\&t=2, e os dados do IPEAdata, disponível em www.ipeadat.gov.br/

${ }^{37}$ Dados da CONAB, disponível em http://www.conab.gov.br/conteudos.php?a=1402\&t=2

${ }^{38}$ Dados disponíveis em http://www.conab.gov.br/OlalaCMS/uploads/arquivos/
Nacional por Amostragem por Domicílio (PNAD, 2014) indicam que permaneceu no país o quadro de pessoas vivendo em situação de Insegurança Alimentar (IA). A PNAD (IDEM, 2014) mostrou que 52,0 milhões de pessoas convivendo com algum grau de $\mathrm{IA}^{39}: 34,5$ milhões em situação de IA leve (aquelas com preocupação quanto ao acesso aos alimentos no futuro); 10,3 milhões em situação de IA moderada (aquelas com limitação de acesso quantitativo aos alimentos); 7,2 milhões em situação de IA grave (aquelas com restrição alimentar, na qual, para pelo menos uma pessoa foi reportada alguma experiência de fome no período investigado). Nas áreas rurais observou-se que índices de IA foram maiores que nas urbanas enquanto na área rural 13,9\%, de domicílios em situação de IA moderada ou grave, na área urbana $6,8 \%$.

Segundo BELIK (2014), a área rural é o território de maior vulnerabilidade social e onde a pobreza é mais profunda, e por isso as ações e programas de SAN necessitam ser intensificadas, sob risco de se enraizar ainda mais a separação entre agricultores produtivos e inviáveis, como vêm sendo denominados os residentes rurais não integrados ao modo hegemônico do agronegócio. Para BELIK (2015) a pobreza rural e a falta de oportunidades de trabalho e renda têm como origem as diferentes condições de acesso aos fatores de produção e a sua baixa capacidade produtiva.

As pesquisadoras Instituto de Pesquisa Aplicada - IPEA (MESQUITA et ali, 2015), com base na PNAD 2013, mostraram um ligeiro aumento da miséria no país, o qual reverteu a tendência de queda observada desde 2005. Os dados da pesquisa mostram que $4 \%$ da população estavam em situação de miséria em 2013, percentual levemente superior ao registrado no ano anterior $(3,6 \%)$.

Além deste quadro adverso a consolidação da estratégia FOME ZERO, entre 2012 a 2015, houve uma inflexão das razões de agir de governo na condução das políticas públicas de SAN, tanto na perspectiva do gasto público quanto na abrangência de sua amplitude de ação e de seus resultados. Houve uma inversão na evolução dos recursos orçamentários federais empenhados para a implantação de políticas públicas de $\mathrm{SAN}^{40}$ cerca de $-16,2 \%$ por ano, com consequências na abrangência das ações e programas de SAN.

${ }^{39}$ Contingente de pessoas equivalentes a população da Espanha (47,1 milh.); e superior a da Argentina (41,4 milh.) e do Canadá ( 35,1 milh. $)$.

${ }^{40}$ Dados do SIGA Brasil/Senado, disponível em SIGA Brasil disponível em https://www12.senado.leg.br orcamento. $<$ 
Por exemplo, no caso da agricultura familiar, entre 2012/15, o volume de recursos gastos do $\mathrm{PAA}^{41}$ passou de $\mathrm{R} \$ 839,2$ para 541,1 milhões, e o número de agricultores familiares participantes passou de 186,0 para 95,8 mil e número de famílias que receberam alimentos foi 22,5 para 13,4 milhões de pessoas. Na modalidade Doação-simultânea o número de agricultores familiares fornecedores reduziu de 129,7 para 70,7 mil e na modalidade Compra Direta de 13,1 para 1,6 mil.

Esse traçado de redução do gasto público do governo se acentua em razão do ajuste econômico recessivo realizado em 2014. A crise econômica mundial, a desaceleração do crescimento econômico e o desequilíbrio financeiro e fiscal das contas públicas influíram na formulação de políticas recessivas.

Consequentemente, desde então, no âmbito dos componentes da demanda interna houve perda de dinamismo no mercado de trabalho. Segundo pesquisa do IBGE entre 2014/16 ocorreu um acréscimo de 53,6\% no contingente de desocupados, e também, na mesma toada, houve uma queda no rendimento real habitual dos trabalhadores que passou de $\mathrm{R} \$ 2420,05$ para 2227,50 (INDICADORES IBGE², 2016).

Mesmo diante: (i) do comportamento dos resultados primário e nominal das contas públicas se agravando, reflexo, em grande medida, da crise econômica internacional e do esgotamento do ciclo de consumo das famílias; (ii) da não impulsão dos investimentos; (iii) de um novo ciclo de elevação da taxa de juros; (iv) de um momento negativo para a questão do emprego e renda dos trabalhadores (em tendência de queda); o governo optou por uma inversão na trajetória de investimentos nas políticas sociais de SAN, apesar das conferencias e encontros de SAN definirem outros caminhos.

A trajetória do SISAN (2003-2016) desafia a noção de continuidade e ampliação, mesmo quando fora bem-sucedida, ao contrário mostra-se que está dependente do contexto econômico e sociopolítico vigente. Já que, as ações de Estado de SAN responderam com adaptações as mudanças nesses contextos conjunturais políticos e econômicos.

9. ESTADO E SISAN: OPORTUNIDADE E LIMITES DA POLITICA.

O projeto teórico-prático do SISAN, ao implicar novas formas de governança na relação entre o Estado e a sociedade civil no exercício de alocação de bens e serviços públicos, focalizou: (i) na participação da sociedade (requerendo o consenso, no qual a gestão pública buscou outras formas de legitimação além das institucionais próprias); (ii) no caráter

${ }^{41}$ Dados do IPEAdata, disponível em www.ipeadat.gov.br/. federativo e republicano (base conceitual de seus instrumentos aplicáveis a outras esferas de governo).

O que foi proposto foi uma estruturação republicana (parceria, consenso e coexistência de poderes sociais e de governo na distribuição de recursos, serviços e bens públicos); vigência de direitos de cidadania (dever do Estado e direito de todo indivíduo estar alimentado e sem fome); democracia representativa (exercício de poder da sociedade civil através de seus representantes); e um arranjo institucional onde a sociedade civil organizada influencia seus interesses na tomada de decisão de execução de distintas políticas sociais.

Essa forma de governança compartilhada Estado e sociedade civil na execução do SISAN expõs algumas questões: (i) o modelo estrutural de governança destinou-se aumentar a capacidade do Estado em garantir direitos sociais e republicanos ou substituiu o Estado de serviços por uma forma de Estado na qual que deu poderes aos indivíduos para competirem na sociedade; (ii) a governança proposta esteve parcialmente adequada para servir como novo modelo regulatório entre o Estado e a sociedade civil, onde os espaços públicos compartilhados, por sua vez, ajudaram muito no problema de atendimento das demandas dos grupos subalternos; (iii) o acesso à pública política de concessão de direitos houve significativa inclusão social, mas que conviveu, ao mesmo tempo, com a exclusão efetiva de indivíduos, grupos, perspectivas sociais e interesses; (iv) o atendimento a direitos, a garantia de oportunidades, o enfrentamento de carências e de situações de vulnerabilidades sociais foram elementos por onde essa política social de SAN atuou como parte de uma efetiva estratégia de combate à pobreza e à desigualdade social quanto ação de Estado.

A discussão sobre Políticas Públicas no Brasil, segundo COSTA (2015) ainda é marcada por uma visão de matriz pluralista que, de certa forma, nega ao Estado a condição do Estado weberiano clássico, a abordagem ignora a natureza do Estado como um poder territorial centralizador, e é incapaz de apreender a natureza contraditória do Estado, essa dupla natureza do Estado. Ela tem uma visão do conflito, da contradição, mais simples, mais chata, mais plana, em que os conflitos aparecem como expressão de interesses préconstituídos, interesses geralmente de visão econômica que se distribuem num certo campo de conflitos em que o Estado arbitra, que o Estado de certa forma coloca em ação apenas quando precisa resolver essas diferenças.

No SISAN o alcance de instituições estatais incorporando a sociedade 
civil abrangeu um universo de manifestações empíricas e científicas, pois a questão da participação social está perpassada tanto por ações determinadas pelo Estado (exercício de poder, a governança compartilhada) como pela prática da organização social na esfera estatal. A execução da política social de segurança alimentar do SISAN transitou num conjunto teórico que vem contribuindo para enriquecer o debate contemporâneo sobre as políticas públicas como os aportes americanos e europeus: neoinstitucionalismo e os modelos de redes de política pública (policy network) ${ }^{42}$.

O caminho traçado pelo SISAN, na última década, sugere reflexão sobre tema Políticas Sociais partindo de pressupostos do Estado para apontar rumos das políticas sociais no que diz respeito ao entendimento de seus sentidos, resultados e limites na garantia de direitos e, de como essas políticas se expressam no aparato de Estado em conjunturas nas quais a sociedade civil parece instrumentalizar o Estado em seu favor.

\section{Considerações finais}

A responsabilização do Estado na garantia de direitos à alimentação eleva o alimento à condição de bem público e problematiza a abrangência de seu caráter de acesso universal e de inclusão social no âmbito do atendimento as necessidades humanas, cuja a privação compromete a vida. Na perspectiva dos rumos e abrangência de uma política social de SAN é fundamental que não se perca a referência constitucional, base de uma perspectiva universalista, inclusiva e de garantia de direitos.

Assim, a identificação da assimetria entre a direito do indivíduo e o reconhecimento desse direito pela ação do Estado na execução das políticas sociais de SAN merece atenção para fins de se compreender as causas e as implicações do comprometimento do caráter universalista e inclusivo da ação do Estado. Em suma, qual a função que Estado se atribui e o que ele realiza em suas ações?

Sem desconsiderar o que foi feito em termos de política social no âmbito do Estado - de experimentação prática dos ditames constitucionais, os resultados alcançados, que por sua vez, mobilizou milhares de pessoas de grupos subalternos organizados na busca por influência sobre a formulação e execução das ações de Estado - se compreender os limites se compreende a totalidade da política de Segurança Alimentar, pois ao definir o todo confere

${ }^{42}$ Ver Romano (2007), Santos (2011) e Teló, Medeiros (2017). sentido mais amplo a política realizada. Para se avaliar o SISAN supõe coloca-lo na dinâmica da realidade, além de se conhecer seus conteúdos e práticas, eles precisam ser analisados como uma ação de Estado, a qual deve garantir direitos, universalizar o acesso e promover a inclusão social.

Assim, para se proceder a um estudo analítico sobre as raízes, a abrangência e os limites de uma política social de Estado se deve compreender a materialidade da estrutura do Estado e o funcionamento desta. Deve procurar dispor de um arcabouço de instrumentos de análise de como a ossatura ${ }^{43}$ do poder político age na composição e execução das políticas públicas, mesmo quando está sob alcance da sociedade civil.

Entender a abrangência e o limite da garantia do direito e do caráter universal e inclusivo de uma política social na materialidade do aparato de Estado trata-se de desvendar os mecanismos e as condições concretas da participação não estatal na política social do SISAN. Pois, o direito de estar alimentado e o reconhecimento do Estado desse direito não é só um problema geral da sociedade, mas uma questão vital para uma parcela da sociedade brasileira, como outras necessidades humanas de viver (educação, saúde; transporte; habitação; saneamento; renda e trabalho); entretanto a abrangência dessas necessidades está limitada a questão da legitimação do Estado $^{44}$.

\section{Referências}

BELIK, W. Segurança alimentar e nutricional e o direito humano à alimentação. In: Ferreira, B. et al. Questão agrária e segurança alimentar. Revista Política Social e Desenvolvimento. Disponível em www. plataformapoliticasocial.com. Acesso em 10/06/2015.

BELIK, W. A heterogeneidade e suas implicações para as políticas públicas no rural brasileiro. Rev. Econ. Sociol. Rural, Brasília, v.53, n1., SOBER, 2015.

\section{BOSCHETTI, I. Avaliação das políticas públicas, programas e}

${ }^{43}$ No sentido dado por Poulantzas (1980), o Estado supõe necessariamente uma organização particular do espaço político sobre o qual exerce o poder.

${ }^{4}$ No sentido posto por OFFE (1984), capacidade do Estado em atender processos de socialização (políticas sociais) que colaboram na manutenção da concordância social ao sistema político vigente. 
projetos sociais. Disponível em http://www.cressrn.org.br/files/arquivos/ V6W3K9PDvT66jNs6Ne91.... Acesso em 02/11/2015.

CAISAN Câmara Intersetorial de Segurança Alimentar e Nutricional. Plano Nacional de Segurança Alimentar e Nutricional: 2012/2015. Brasília: CAISAN, 2011

CARDOSO DE MELLO, J M. O capitalismo tardio: contribuição à revisão crítica da formação e do desenvolvimento da economia brasileira. São Paulo: Brasiliense, 1982.

CONSEA (Conselho de Segurança Alimentar e Nutricional). Princípios e Diretrizes de uma Política de Segurança Alimentar e Nutricional. Cartilha Lei de Segurança Alimentar e Nutricional: conceitos, Lei 11.346, de 15 de setembro de 2006. Disponível em http://www4.planalto. gov.br/CONSEA/publicacoes/cartilha-losan-portugues, 2007. Acesso em 05/12/2017

CONSEA (Conselho Nacional de Segurança Alimentar e Nutricional). Construção do Sistema e da Política Nacional de Segurança Alimentar e Nutricional: a experiência brasileira. Brasília: FAO (Organização das Nações Unidas para a Alimentação e a Agricultura) / IICA (Instituto de Cooperación para la Agricultura), 2009.

CONSEA (Conselho de Segurança Alimentar e Nutricional). A Segurança Alimentar e Nutricional e o Direito Humano à Alimentação Adequada no Brasil: indicadores e monitoramento da constituição de 1988 aos dias atuais. Brasília: CONSEA, 2010.

CORRAZA, G.; FERRARI FILHO, F. A política econômica do Governo Lula no primeiro ano de mandato: perplexidade, dilemas, resultados e alternativas. Indicadores Econômicos, Porto Alegre, v.32, n.1, 2004.

COSTA, V. Políticas públicas no Brasil: uma agenda de pesquisa. Idéias Rev. Inst. Filos. Ciênc. Hum, Campinas, v.6, n.2, 2015.

DRAIBE, S M. Avaliação de implementação: esboço de uma política metodológica de trabalho em política pública. In: BARREIRA; CARVALHO
(Orgs.) Tendências e perspectivas na avaliação de programas sociais. São Paulo: IEE/PUC, 2001.

FAGNANI, E. Previdência social e desenvolvimento econômico. Texto para Discussão. IE/UNICAMP n. 140. Campinas/SP: UNICAMP, 2008.

FERNANDES, F. Marx, Engels, Lenin: história em processo. São Paulo: Expressão Popular, 2012.

FREY, M P K. Políticas públicas: um debate conceitual e reflexões referentes à pratica da análise de políticas públicas no Brasil. Revista de Planejamento e Políticas Públicas, Brasília, n.20, IPEA, 2000.

GRISA, C. As ideias na produção de políticas públicas: contribuições da abordagem cognitiva. In: BONNAL, P; LEITE, SP (Orgs.) Análise Comparada de políticas agrícolas: uma agenda em transformação. Rio de Janeiros: Muad X, 2011.

HUBERMAN, L. História da riqueza do homem. Rio de Janeiro: ZAHAR, 1979.

INDICADORES IBGE. Pesquisa Mensal de Emprego Fevereiro 2016. Brasília: IBGE, 2016. Disponível em www.ibge.gov.br/Trabalho_e Remdimento/Pesquisa Mensal_... Acesso em 14/06/2017.

MACEDO D C, et ali. A construção da política de segurança alimentar e nutricional no Brasil. Rev. Simbio-Logias, v.2, n.1. Botucatu/SP: UNESP, 2009.

MASSARDIER, G. Redes de Política Pública. In: SARAIVA, E; FERRAREZI, E. (orgs). Políticas públicas. Coletânea, Brasília: ENAP, 2006.

MESQUITA, A C S et ali. Política Assistência Social. In: Políticas sociais: acompanhamento e análise, v.23. Brasília: IPEA, 2015

OCDE (A Organização para a Cooperação e Desenvolvimento Económico 
ou Econômico). Relatórios econômicos da OCDE Brasil (resumo em português), 2015. Disponível em http://www.oecd.org/eco/surveys/Brasil2015-resumo.pdf.

OFFE, C. Problemas estruturais do Estado capitalista. Trad. Bárbara Freitag. Rio de Janeiro: Tempo Brasileiro, 1984.

OLIVEIRA, F A. Economia e política das finanças públicas no Brasil. São Paulo: HUCITEC, 2012.

PNAD (Pesquisa Nacional por Amostra de Domicílios). Segurança Alimentar, 2013. Rio de Janeiro: IBGE, 2014.

PNUD (Programa das Nações Unidas para Desenvolvimento). Relatório do Desenvolvimento Humano 2015: o trabalho como motor do desenvolvimento humano. New York: PNUD, 2015.

POULANTZAS, N. O Estado, o poder, o socialismo. Rio de Janeiro: Edições Graal, 1980.

SILVA, R P et ali. PRONAF e a produção familiar. Retratos de Assentamentos, Araraquara, v 18, n 2., UNIARA, 2014. 